\title{
Chronic cluster headache and the pituitary gland
}

\author{
Annelien De Pue ${ }^{1 *}$, Bart Lutin $^{2}$ and Koen Paemeleire ${ }^{1}$
}

\begin{abstract}
Background: Cluster headache is classified as a primary headache by definition not caused by an underlying pathology. However, symptomatic cases of otherwise typical cluster headache have been reported.

Case presentation: A 47-year-old male suffered from primary chronic cluster headache (CCH, ICHD-3 beta criteria fulfilled) since the age of 35 years. A magnetic resonance imaging (MRI) study of the brain in 2006 came back normal. He tried several prophylactic treatments but was never longer than 1 month without attacks. He was under chronic treatment with verapamil with only a limited effect on the attack frequency. Subcutaneous sumatriptan $6 \mathrm{mg}$ injections were very effective in aborting attacks. By February 2014 the patient developed a continuous interictal pain ipsilateral to the right-sided cluster headache attacks. An indomethacin test (up to $225 \mathrm{mg} /$ day orally) was negative. Because of the change in headache pattern we performed a new brain MRI, which showed a cystic structure in the pituitary gland. The differential diagnosis was between a Rathke cleft cyst and a cystic adenoma. Pituitary function tests showed an elevated serum prolactin level. A dopamine agonist (cabergoline) was started and the headache subsided completely. Potential pathophysiological mechanisms of pituitary tumor-associated headache are discussed.

Conclusion: Neuroimaging should be considered in all patients with $\mathrm{CCH}$, especially those with an atypical presentation or evolution. Response to acute treatment does not exclude a secondary form of cluster headache. There may be shared pathophysiological mechanisms of primary and secondary cluster headache.
\end{abstract}

Keywords: Cluster headache, Pituitary gland, Secondary headache

\section{Background}

Cluster headache $(\mathrm{CH})$ is classified as a primary headache by definition not caused by an underlying pathology. However, numerous symptomatic cases of otherwise typical $\mathrm{CH}$ have been reported. We want to report a case of a man with typical chronic cluster headache $(\mathrm{CCH})$ and a pituitary lesion only found on repeat MRI. Potential mechanisms underlying this association are discussed. We hope this will be useful to other clinicians taking care of patients suffering from this devastating condition [1].

\section{Case presentation}

A 47 year-old man was diagnosed with $\mathrm{CH}$ at the age of 35. A 1,5 Tesla MRI of the brain in another hospital was reportedly normal. The patient came under our care in 2011. The headache attacks and pattern were compatible

\footnotetext{
* Correspondence: annelien.depue@Ugent.be

${ }^{1}$ Department of Neurology, Ghent University Hospital, De Pintelaan 185,

B-9000 Ghent, Belgium

Full list of author information is available at the end of the article
}

with a primary $\mathrm{CCH}$ diagnosis according to the criteria of the International Headache Society (ICHD-3 beta, 3.1.2) [2]. The patient described attacks of strictly right-sided orbitotemporal headache associated with ipsilateral tearing and nasal congestion. The attacks lasted from 20 to 60 min, with a frequency up to 4 attacks per day, often including one attack at night. The most consistent trigger was alcohol intake. Subcutaneous sumatriptan $6 \mathrm{mg}$ injections were very effective in aborting attacks, inhaled high-flow oxygen was not. Despite different prophylactic treatments (verapamil up to $480 \mathrm{mg} /$ day, lithium up to $800 \mathrm{mg} /$ day, topiramate up to $400 \mathrm{mg} /$ day) the $\mathrm{pa}$ tient was never longer than 1 month without attacks. By February 2014 the patient developed a continuous interictal pain ipsilateral to the right-sided $\mathrm{CH}$ attacks. At that point in time he was under chronic treatment with verapamil (maximal tolerated dose of $560 \mathrm{mg} /$ day) for 6 months with only a mild effect on attack frequency. An indomethacin test (up to $225 \mathrm{mg} /$ day orally) was negative. Because of the change in headache pattern we decided
望 Springer

(c) 2016 De Pue et al. Open Access This article is distributed under the terms of the Creative Commons Attribution 4.0 International License (http://creativecommons.org/licenses/by/4.0/), which permits unrestricted use, distribution, and reproduction in any medium, provided you give appropriate credit to the original author(s) and the source, provide a link to the Creative Commons license, and indicate if changes were made. 
to perform a new brain MRI, which showed a cystic structure in the pituitary gland (Fig. 1). The differential diagnosis was between a Rathke's cleft cyst or a cystic adenoma. Pituitary function tests (PFTs) came back normal, except for an elevated prolactin level $(68.4 \mu \mathrm{g} /$ $\mathrm{L}$, normal values $4-17 \mu \mathrm{g} / \mathrm{L}$ ) and a low free testosterone level (4.44 ng/dL, normal values 6-25 ng/dL). This could be due to verapamil-induced hyperprolactinemia or a prolactinoma. There was no galactorrhea, gynaecomastia, or erectile dysfunction (but he acknowledged a low libido), and visual fields were full. The patient was not willing to stop the treatment with verapamil as he feared an increase in cluster attack frequency. The patient was referred to an endocrinologist, who started carbergoline, a dopamine agonist, at a dose of $0,25 \mathrm{mg}$ twice a week. Within a few weeks after the start of the cabergoline treatment the $\mathrm{CH}$ attacks subsided completely and verapamil could be successfully stopped. The serum prolactin and testosterone levels normalized. A repeat MRI in October 2015 demonstrated a $30 \%$ reduction in size of the cystic pituitary lesion. At present the patient has been on carbergoline treatment for 1,5 year and the cluster headaches haven't returned ever since and prolactin levels remained within normal range. Interestingly, the patient reports to experience a new type of unilateral frontotemporal headache attacks since about 6 months. These attacks are milder and shortlasting (seconds), and the pain is rather stabbing. There are no associated cranial autonomic symptoms. These attacks are not disabling and the patient does not need treatment for them. We have labeled these probable short-lasting unilateral neuralgiform headache attacks (ICHDI-3 beta, 3.5.3) within the given context.

\section{Discussion}

\section{Secondary cluster headache}

The lesion in the pituitary and the headaches could just be a co-occurrence. However the temporal relationship between the initiation of carbergoline treatment and disappearance of the cluster headache attacks suggests a potential causal relationship with the pituitary lesion and (worsening of) the headache condition. This adds to numerous recent reports of secondary cluster-like headache (CLH). By definition before concluding to a primary headache potential causative disorders should be excluded to rule out a secondary CLH. Edvardsson reviewed 63 cases of symptomatic $\mathrm{CH}$ associated with vascular problems $(44 \%)$, tumours $(40 \%)$ or inflammation/infection (11\%) [3]. Of the 63 cases $48 \%$ fulfilled the criteria for $\mathrm{CH}$. A larger cohort of 156 cases of CLH showed a similar distribution of causative disorders [4]. On first observation, $50 \%$ of CLH perfectly mimicked $\mathrm{CH}$ at presentation [5]. Furthermore, the response to typical $\mathrm{CH}$ medications does not exclude a secondary form. Red flags could be older age at onset, abnormalduration/frequency/localization, change in clinical characteristics or response to treatment, or an abnormal neurological/general examination $[4,5]$. These findings suggest that neuroimaging should be considered in all patients with $\mathrm{CH}$, even typical cases. The ICHDIII beta criteria for secondary headache disorders require evidence of causation, which includes that headache has significantly worsened in parallel with worsening of the presumed causative disorder' and 'headache has significantly improved (or disappeared) in parallel with improvement of the presumed causative disorder'. In our patient neuro-imaging was done early in his headache trajectory and results came back normal. However, in

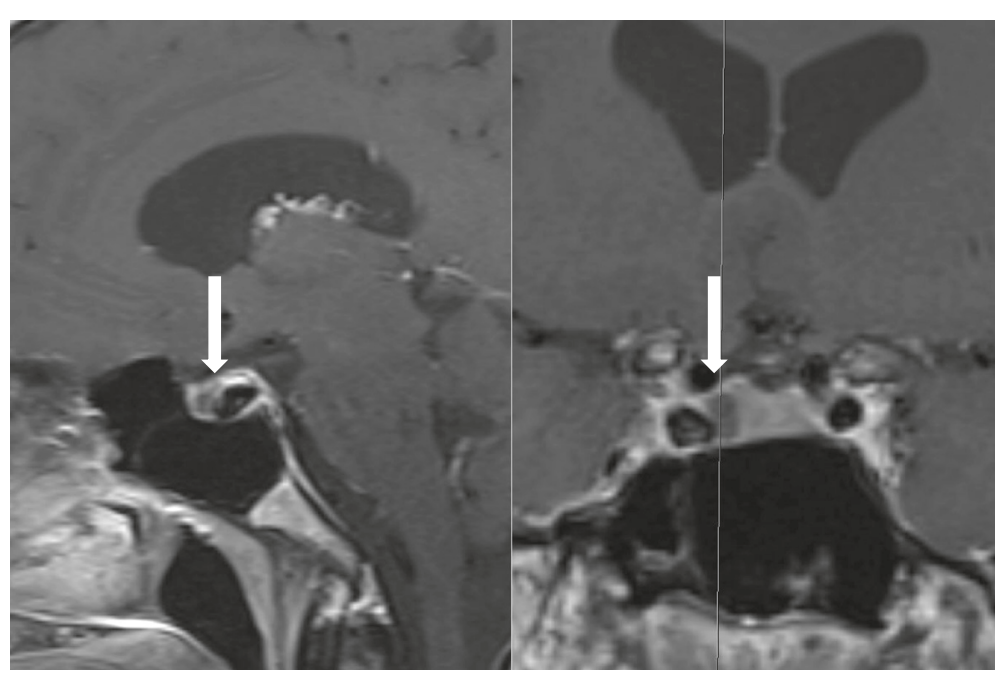

Fig. 1 MRI of the pituitary gland. T1 contrast-enhanced images. Left image: sagittal view. Right image: coronal view. White arrow indicates cystic structure in the pituitary 
retrospect we noted that the spatial resolution of the initial MRI of the brain at the level of the pituitary gland was too low to exclude that the cystic structure (Fig. 1) was already present. Even though interictal headache in cluster headache is not an uncommon phenomenon [6], it was the change in headache history in our patient that sparked repeat neuro-imaging.

\section{Pathophysiology}

The pathophysiology of secondary CLH associated with pituitary disorders is not well-known. A few hypotheses are considered and summarized in Fig. 2. The long-held theory that $\mathrm{CH}$ was the related to a cerebrovascular problem radically changed in the late nineties with $\mathrm{CH}$ attacks being recoined as neurovascular in origin and with an important role for the hypothalamic-pituitary axis in the generation of these attacks. Functional imaging studies (fMRI, PET), neuro-endocrine changes (melatonin, cortisol, testosterone, ...) and the circadian/ circannual rhythmicity all point to an alteration in the hypothalamus [7-10]. Also lithium, which is one of the known preventative treatment options for $\mathrm{CH}$, is heterogeneously distributed in the brain and seems to accumulate in the hypothalamus and pituitary gland [11, 12]. The pain during cluster headache attacks is attributed to activation of the trigeminovascular system and cranial autonomic symptoms are generated via the trigeminalautonomic reflex [13-15].

A structural lesion in the hypothalamic-pituitary axis could lead to an autonomic imbalance resulting in an attack-wise presentation of complaints. Others have suggested that the headache due to a lesion in the pituitary is a result of dura mater stretch or invasion of the cavernous sinus. Indeed, the cavernous sinus lateral to the sella turcica contains the ophthalmic and maxillary branches of the trigeminal nerve as well as the internal carotid artery, which are structures that can generate pain. However, in a systematic study of headache in patients with pituitary tumors, no correlation between pituitary volume and headache or between headache and cavernous sinus invasion was found [16]. Pituitary tumor-associated headache may have a biochemicalneuroendocrine basis rather than a structural one [16]. Finally, there is some evidence for the role of "nociceptive peptides" [17]. The presence of calcitonin gene related peptide (CGRP) or substance $P$ in pituitary tumors does not seem to be associated with headache [15]. Other candidate peptides are vasoactive intestinal peptide (VIP), pituitary adenylate cyclase-activating protein and neuropeptide $\mathrm{Y}$.

\section{Pituitary function tests, prolactin and dopamine agonist}

A few additional questions are provoked by this case. Is the raised serum prolactin level due to the lesion in the pituitary or induced by the high dose of verapamil? Is the effect of cabergoline proving that the lesion is a prolactinoma and the cause of the headache? Is the positive effect of carbergoline due to the normalization of serum prolactin? Is there a need for screening with PFT's in $\mathrm{CH}$ ?

There are physiologic, pituitary and systemic (including medications, such as verapamil) causes of hyperprolactinemia [18]. Pituitary causes include prolactin-secreting pituitary adenoma or disconnection hyperprolactinemia due to a lesion that compresses the pituitary stalk [18]. L-type calcium channel blockers, such as verapamil, are known to cause a doubling of serum prolactin levels [19]. Since the patient was reluctant to stop verapamil because of fear increased $\mathrm{CH}$ attack frequency, we could not distinguish between both mechanisms prior to initiation of cabergoline treatment. Cabergoline is a long acting D2 dopamine receptor agonist that inhibits prolactin secretion. There

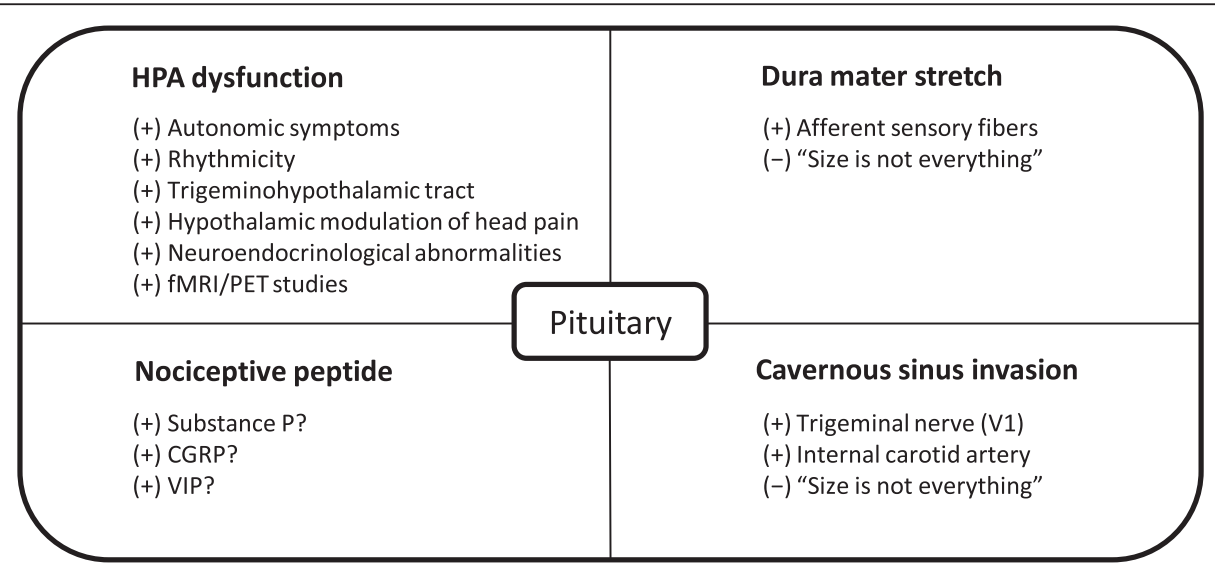

Fig. 2 Potential pathophysiological links with the pituitary gland in cluster headache. (+) arguments pro (-) arguments con. "Size is not everything" is a reference to an article of Levy et al. [16]. V1 is the ophthalmic branch of the trigeminal nerve. HPA = hypothalamic-pituitary axis. The figure is further explained in the text under the heading "pathophysiology" 
are reported cases of microprolactinomas manifesting with headache that resolved after administration of a dopamine agonist [20, 21], but there are also reports stating the opposite [22]. The effect of cabergoline on headache doesn't seem to be associated with the normalization of serum prolactin [20]. Potential mechanisms include alterations to the pain-modulating dopaminergic system and carbergoline, an ergot derivative, also possesses significant affinity for certain subtypes of serotonergic and adrenergic receptors. A normal MRI of the brain does not exclude a microadenoma [23], and PFT's should therefore be considered in (refractory) patients with $\mathrm{CCH}$ or other (TAC).

\section{Conclusion}

Neuroimaging should be considered in all patients with $\mathrm{CCH}$, especially those with an atypical presentation or evolution. When performing brain imaging it seems important to pay extra attention to the pituitary/parasellar region. Response to acute treatment does not exclude a secondary form of $\mathrm{CH}$. PFTs should be considered in patients suffering from (refractory) $\mathrm{CCH}$ or other TACs. Cabergoline may have a dramatic effect on $\mathrm{CH}$ in patients with coexistent hyperprolactinemia.

\section{Consent}

The patient gave written informed consent to have his case published.

\section{Abbreviations}

CCH: chronic cluster headache; CGRP: calcitonin gene-related peptide; $\mathrm{CH}$ : cluster headache; CLH: cluster-like headache; ICHD-3 beta: The International Classification of Headache Disorders Third Edition, beta version; mg: milligram: MRI: magnetic resonance imaging; ng/dl: nanogram per deciliter; PFT: pituitary function tests; TAC: trigeminal autonomic cephalalgias; TCC: trigeminocervical complex; VIP: vasoactive intestinal peptide; $\mu \mathrm{g} / \mathrm{l}$ : microgram per liter.

\section{Competing interests}

The authors declare that they have no competing interests.

\section{Author's contributions}

ADP drafted the manuscript and made Fig. 2. BL provided the MRI images. KP had substantial contribution to the manuscript and its content. All authors read and approved the final manuscript.

\section{Author details}

1Department of Neurology, Ghent University Hospital, De Pintelaan 185, B-9000 Ghent, Belgium. ²Department of Radiology, Ghent University Hospital, Ghent, Belgium.

Received: 14 January 2016 Accepted: 7 March 2016

Published online: 11 March 2016

\section{References}

1. Marteletti P, Mitsikostas D-D (2015) Cluster headache: a quasi-rare disorder needing reappraisal. J Headache Pain 16:59

2. Headache Classification Committee of the International Headache Society (IHS) (2013) The International classification of headache disorders, 3rd Edition (beta version). Cephalalgia 33(9):629-808

3. Edvardsson B (2014) Symptomatic cluster headache: a review of 63 cases. Springer Plus 3:64

4. Mainardi F, Trucco M, Maggioni F et al. (2010) Cluster-like headache. A comprehensive reappraisal. Cephalalgia 30:399-412
5. Wilbrink LA, Ferrari MD, Kruit MC et al. (2009) Neuro-imaging in trigeminal autonomic cephalgias : when, how, and of what? Curr Opinion Neurol 22(3):247-253

6. Marmura MJ, Pello SJ, Young WB (2010) Interictal pain in cluster headache. Cephalalgia 30(12):1531-1534

7. May A, Bahra A, Buchel C et al. (1998) Hypothalamic activation in cluster headache attacks. Lancet 351:275-278

8. Sprenger T, Boecker H, Tolle TR et al. (2004) Specific hypothalamic activation during a spontaneous cluster headache attack. Neurology 62:516-517

9. Morelli N, Pesaresi l, Cafforio G et al. (2008) Functional magnetic resonance imaging in episodic cluster headache. J Headache Pain 10:11-14

10. Leone M, Bussone G (1993) A review of hormonal findings in cluster headache Evidence for hypothalamic involvement. Cephalalgia 13:309-317

11. Edelfors S, Gothgen I (1971) Distribution of electrolytes within the brain in lithium treated rats. Acta Pharmacol Toxicol 29(4):11, abstract

12. Pfeifer WD, Davis LC, van der Velde CD (1976) Lithium accumulation in some endocrine tissues. Acta Biol Med Ger 35(11):1519-23

13. May A (2005) Cluster headache: pathogenesis, diagnosis, and management. Lancet Neurol 366:843-855

14. Goadsby PJ (2002) Pathophysiology of cluster headache: a trigeminal autonomic cephalgia. Lancet Neurol 1:251-257

15. Nesbitt AD, Goadsby PJ (2012) Cluster headache. BMJ 344:37-42

16. Levy MJ, Jäger R, Powell M et al. (2004) Pituitary volume and headache size is not everything. Arch Neurol 61:721-725

17. Levy MJ, Classey JD, Maneesri S, Meeran K, Powell M, Goadsby PJ (2004) The association between calcitonin gene-related peptide (CGRP), substance P and headache in pituitary tumours. Pituitary 7(2):67-71

18. Tritos NA, Klibanski A (2015) Hyperprolactinemia. JAMA 314(16):1742-3

19. Kelley SR, Kamal TJ, Molitch ME (1996) Mechanism of verapamil calcium channel blockade-induced hyperprolactinemia. Am J Physiol 270(1 Pt 1):E96-100

20. Kallestrup MM, Kasch H, Österby T et al. (2014) Prolactinoma-associated headache and dopamine agonist treatment. Cephalalgia 34(7):493-502

21. Gabrielli M, Gasbarrini A, Fiore G et al. (2002) Resolution of migraine with aura after successful treatment of a pituitary microadenoma. Cephalalgia 22:149-150

22. Levy M, Matharu MS, Goadsby PJ (2003) Prolactinomas, dopamine agonist and headache: two case reports. Eur J Neurol 10:169-174

23. Hauache OM, Rocha AJ, Maia AC et al. (2002) Screening for macroprolactinaemia and pituitary imaging studies. Clin Endocrinol (Osf) 57(3):327-331

\section{Submit your manuscript to a SpringerOpen ${ }^{\circ}$ journal and benefit from:}

- Convenient online submission

- Rigorous peer review

- Immediate publication on acceptance

- Open access: articles freely available online

- High visibility within the field

- Retaining the copyright to your article

Submit your next manuscript at springeropen.com 